\title{
Respuesta al comentario de Gustavo Paz
}

\section{Reply to comment by Gustavo Paz}

\section{Julio Pinto VAllejos - DANIEl Palma Alvarado}

\section{Resumen}

Este escrito es una reacción a las observaciones formuladas a nuestro libro $E l$ orden y el bajo pueblo, donde comparamos la implantación y reproducción de los regímenes encabezados por Juan Manuel de Rosas en Buenos Aires y por la elite portaliana en Chile, entre las décadas de 1830 y 1850. Discute la pertinencia del ejercicio comparativo y pondera la incidencia de variables estructurales y coyunturales que explicarían las semejanzas y particularidades observadas en la estructuración del orden postcolonial en cada uno de los casos analizados.

Palabras clave: historia comparada - rosismo régimen portaliano - orden postcolonial sectores populares

\begin{abstract}
This text responds to the comments made by historian Gustavo Paz to our book El orden y el bajo pueblo, where we compare the establishment and reproduction of the regimes headed by Juan Manuel de Rosas in Buenos Aires and Diego Portales in Chile, between the decades of 1830 and 1850 . It discusses the appropriateness of the comparative approach, and weighs the impact of structural and conjunctural factors on the similarities and particularities exhibited by the implantation of the postcolonial order in the two cases under inspection.
\end{abstract}

Keywords: comparative history - Rosas Portales - postcolonial order - popular groups

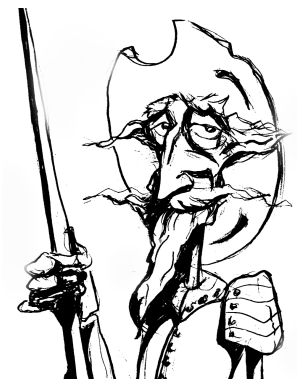

Recibido con pedido de publicación el 5 de octubre de 2016

Aceptado para su publicación el 30 de octubre de 2016

Versión definitiva recibida el 15 de noviembre de 2016

Julio Pinto Vallejos, Universidad de Santiago de Chile (USACH), Chile; e-mail: julio.pinto@usach.cl

Daniel Palma Alvarado, Departamento de Historia, Universidad Alberto Hurtado (UAH), Chile; e-mail: dpalma@uahurtado.cl 
Apreciamos el comentario de Gustavo Paz, pues incita a profundizar la discusión sobre la validez del ejercicio comparativo, a la vez que nos alerta sobre los riesgos que esta opción implica. No solo se observan importantes diferencias de escala entre las dos zonas comparadas, nos advierte, sino que sus estructuras agrarias y sociales, la naturaleza de sus élites, y la herencia del orden colonial, configuran otras tantas barreras para emprender una comparación válida y sostenible entre ambas experiencias. Lo que se anida detrás de estos juicios, pensamos, es una interpelación a la tentativa misma de comparar trayectorias históricas que, por su propia condición de tales (históricas), siempre exhibirán rasgos y ritmos particulares, que solo forzando mucho el despliegue analítico pueden "reducirse" a fórmulas asimilables. La búsqueda de generalidades resulta para el historiador habitualmente incómoda, más propia de la mirada "homogeneizadora" de las otras ciencias sociales que de la sensibilidad hacia lo particular y hacia el cambio que caracteriza (y enorgullece) a nuestra disciplina.

Frente a tal interpelación, que reconocemos haber extremado un tanto en sus contrapuntos para efectos de estructurar mejor nuestra respuesta, debemos partir señalando que, en tanto historiadores, compartimos la preocupación de Gustavo Paz por cautelar las particularidades y los tiempos propios de cada experiencia histórica. En tal registro, debemos enfatizar que nuestro objeto no ha sido tanto establecer "leyes generales" que den cuenta de manera uniforme de procesos tan complejos, variados y multifacéticos como lo fueron los de construcción de órdenes políticos en la post-independencia, como el de, a partir de ciertas similitudes observables, fijar el lente tanto en lo similar como en lo diferente, para desde allí elaborar un análisis más matizado de cada uno de los casos tratados. Dicho de otra forma, lo que nos propusimos fue rescatar tanto lo propio como lo compartido, a partir de coordenadas iniciales seleccionadas en función de sus potencialidades analíticas, para luego aventurar algunas hipótesis que dieran cuenta de lo uno tanto como de lo otro, pero sin por ello aspirar a una suerte de matriz explicativa que nos ahorre el análisis caso a caso.

El punto específico de partida elegido para iniciar nuestro análisis, bastante establecido tanto por la historiografía como por las propias fuentes, fue la común búsqueda de un orden político y social estable, que pusiera fin a las conmociones provocadas por el proceso independentista y sus secuelas. En la priorización de esa tarea, los regímenes de Portales y de Rosas fueron de una sola opinión. Para llevarla a cabo, sin embargo, se vieron empujados a entablar relaciones bastante diferenciadas con sus respectivos sectores populares, precisamente en virtud de las diferencias entre sus respectivas configuraciones societarias, entre el carácter de su demografía y territorio, y entre las inclinaciones y necesidades de sus respectivos actores sociales. En otras palabras, a partir de un desafío común, las particularidades de cada caso impusieron el recurso a estrategias y alianzas diferentes, que finalmente desembocaron en "soluciones" también diferentes, que nos interesó rescatar 
precisamente en función de tales diferencias. En ese contexto, las "heterogeneidades" que para Gustavo Paz problematizan el recurso a la comparación, son para nosotros factores que enriquecen el ejercicio comparativo, y que nos permiten deducir conclusiones diferenciadas para cada caso, sin por ello negar el punto de partida común que a final de cuentas hace posible esta aproximación metodológica.

Menos problemática le hubiese parecido a Gustavo Paz nuestra aventura si se hubiesen comparado formaciones socio-económicas que él estima más análogas, como serían las de Chile y las provincias norteñas del Río de la Plata que él conoce muy bien de sus trabajos anteriores. Coincidimos en que las "variables estructurales" heredadas del período colonial presentan en estos casos analogías mucho más aparentes, y reconocemos que la conducta igualmente "levantisca" de los actores populares norteños sugiere que dichas variables tal vez no habrían tenido un valor explicativo tan relevante como el que les atribuimos en una de nuestras hipótesis. Desconocedores de la historia de dichas provincias, se trata efectivamente de una reflexión que no emprendimos durante el curso de la investigación, y que el bienvenido aporte de Gustavo Paz nos instala ahora como un factor a considerar. Sin embargo, insistimos, nuestra selección de la Buenos Aires rosista obedeció a la analogía de propósitos que visualizamos entre ella y la propuesta portaliana, y que en el caso de Salta y Jujuy no sabemos si se verificó con igual nitidez en algún grupo de poder. Así y todo, y por las razones señaladas más arriba, las diferencias "estructurales" entre la sociedad bonaerense y la chilena (que, repetimos, para el período en estudio no se extendía mucho más allá de nuestro Valle Central), nos parecieron en su momento un elemento analíticamente tan fructífero como podrían serlo las analogías sobre las que ahora se nos llama la atención. Puestas en clave sociológica, ambas nos ayudan a precisar mejor cuáles serían las variables "dependientes" y las "independientes" de nuestro estudio, tal como lo insinúa Gustavo Paz en otro pasaje de su comentario al que nos referiremos más adelante. En todo caso, rescatamos de esta observación el estímulo que ella implica en cuanto a extender y multiplicar el ejercicio comparativo.

Otra crítica emanada del comentario de Gustavo Paz es la que dice en relación con la "rigidez", en el sentido de "atemporalidad", con que, a su parecer, habríamos abordado el comportamiento de las élites rosista y portaliana, descuidando los matices y desplazamientos que una mirada más atenta a las coyunturas y a las cambiantes correlaciones de poder habría permitido resaltar. Según nos dice, una mirada de ese tipo habría trasladado la "naturaleza" de dichas élites a la posición de una variable más dependiente que independiente, perdiendo su "centralidad en la explicación de la implantación de ambos órdenes políticos". En un sentido estricto, debemos reconocer que la crítica no carece de fundamentos. Cuando se comparan dos regímenes que, para los efectos de nuestro análisis, abarcan más de dos décadas, existe efectivamente la tentación de fijar la atención en aquellos rasgos aparentemente 
más permanentes, perdiendo el sentido de flujo y transformación que, subrayando nuevamente su fina sensibilidad historiográfica, Gustavo Paz no quisiera ver menoscabado. Se trata de una admonición que tendremos ciertamente muy presente para trabajos futuros de esta índole. Pero en lo que respecta al hipotético efecto de disminuir el poder explicativo de la "naturaleza" de las élites bajo comparación al momento de dar cuenta de sus relaciones con el mundo popular, no nos parece tan claro que nuestra hipótesis haya descansado en una tal "naturalización" de dichas élites. Lo que postulamos fue que los mayores o menores grados de fragmentación de esos grupos, pudieron haberlos inducido a adoptar posturas más o menos negociadoras respecto de los grupos populares. En consecuencia, para validar la crítica de Paz, lo que habría que observar es si esa fragmentación aumentó o disminuyó durante el período en estudio, y si tal aumento o disminución encontró un correlato en sus tratativas con el mundo plebeyo. Hay indicios que sugieren que ello pudo ser así. La todavía poco estudiada década final del rosismo, cuando el aquietamiento de los conflictos internos estabilizó temporalmente los destinos del régimen, podría haber dado lugar a un aflojamiento, o al menos una ritualización, de sus alianzas plebeyas. Del mismo modo, las crisis políticas que sacudieron el decenio del muy "portaliano" presidente Manuel Montt (decenio no cubierto en nuestro libro), y que derivaron en dos guerras civiles de envergadura, también valorizaron temporalmente dichas alianzas para el caso chileno. Así las cosas, el análisis más matizado al que nos invita Gustavo Paz efectivamente podría ayudarnos a afinar el poder explicativo de nuestra hipótesis sobre los efectos de la fragmentación de las élites sobre su "política plebeya", pero sin que ello implique necesariamente "degradarla" de variable independiente a dependiente.

El ejercicio comparativo y las observaciones de nuestro comentarista también nos han permitido levantar preguntas que contribuyen a ampliar la problematización original con la que encaramos esta investigación. Destacamos en particular la reflexión sobre la movilización popular y su incidencia en el diseño de dispositivos ordenadores más o menos incluyentes. Si en un comienzo partimos del supuesto que la politización plebeya en Buenos Aires sumada a las oportunidades abiertas por la gran demanda militar y laboral-, era la clave para entender la introducción de los mecanismos de negociación y la adhesión de amplios sectores de la plebe porteña al proyecto rosista, mientras en el caso de Chile la elite conservadora prescindió de todo entendimiento con una masa popular políticamente menos activada y fuertemente despreciada por sus usos y costumbres; el "peso de la herencia del orden social colonial", según argumenta Gustavo Paz, emerge como una variable a analizar más detenidamente. La configuración y trayectoria de los sectores populares, en tanto antecedente del mayor o menor protagonismo alcanzado durante $\mathrm{y}$ 
después de la coyuntura independentista, se constituye ciertamente en un factor a potenciar en futuras investigaciones.

Del mismo modo, el carácter multifacético de las conductas plebeyas y de la acción colectiva durante el período, requiere adoptar una perspectiva que pueda dar cuenta de todo aquello que, en virtud de nuestra opción metodológica de reconstruir las representaciones y las políticas "desde arriba", no recibió toda la atención necesaria. La movilización miliciana o electoral, las montoneras, la resistencia cotidiana al trabajo compulsivo en estancias o centros mineros, el recurso popular a la justicia, la defensa de inveteradas tradiciones festivas o los malones indígenas; pero también la deferencia y adaptación al nuevo orden, revelan una diversidad de situaciones que la mirada homogeneizadora de las elites rosista y portaliana solo capturó parcialmente. En otras palabras, creemos que las respuestas populares a la estrategia disciplinadora impulsada por ambos regímenes autoritarios ameritan un análisis sistemático y exhaustivo, atento, por ejemplo, a los contrastes entre las zonas urbanas y rurales, entre sectores económicos más o menos vinculados a la exportación de materias primas y alimentos, o entre regiones fronterizas y de poblamiento más antiguo.

Queremos recalcar, finalmente, que pese a las diferencias entre los regímenes rosista y portaliano, tanto en términos de su configuración estructural como en relación a su interacción con el bajo pueblo, lo que los igualó fue la unidad de propósitos y la implantación de un orden sociopolítico donde la apelación al poder hegemónico de la ley en un marco formalmente republicano, se combinó con la violencia y la arbitrariedad cada vez que se estimó necesario. En ese sentido, la tan manida "excepcionalidad chilena" y la comprensión del rosismo como prototipo del "caudillismo", impidieron durante largo tiempo apreciar cabalmente las coincidencias estratégicas que el ejercicio comparativo ha evidenciado. 